\title{
Cross-modal transfer as a function of similarities between training tasks in classical conditioning of the rabbit
}

\author{
PHOEBE E. HOLT and E. JAMES KEHOE \\ University of New South Wales, Kensington, New South Wales, Australia
}

\begin{abstract}
The present experiments examined transfer of training from visual to auditory sensory modalities in classical conditioning of the rabbit's nictitating membrane response. Experiment $1 \mathrm{ex}$ amined transfer from initial training with a single visual CS to subsequent auditory discrimination training, and Experiment 2 examined transfer from visual discrimination training to auditory discrimination training. The major findings were that (1) initial conditioning of a visual CS facilitated the overall rate of $\mathrm{CR}$ acquisition to the auditory CSs separate from the requirements for discrimination learning (Experiments 1 and 2), and (2) initial visual discrimination training facilitated auditory discrimination learning (Experiment 2). Thus, the animals appeared to encode separately both contiguous CS-US relations and CS+ versus CS- relations during initial visual training. The results are discussed with respect to theories of extradimensional transfer.
\end{abstract}

Transfer of training across sensory modalities is one form of extradimensional transfer in which transfer testing is conducted with stimuli that were either constant in original training or introduced only at the beginning of transfer testing (Thomas, 1970, p. 317). Operationally, three types of cross-modal transfer have been identified. First, "immediate transfer'" can be said to have occurred when, after training with stimuli in one modality, an alteration in performance is observed on the very first presentations of stimuli in a second modality. For example, Seraganian and Popova (1976) reported immediate transfer of an instrumental leg flexion response in dogs between a visual discrimination and an auditory discrimination in which the discriminative stimuli in the two tasks shared the same temporal patterns (intermittent vs. continuous) (cf. Meck \& Church, 1982). Second, " general transfer" can be said to have occurred when prior training enhances the rate or asymptote of response acquisition to stimuli in a second modality. For example, Thomas, Miller, and Svinicki (1971) showed that rats given discrimination training between two light intensities learned a tone frequency discrimination faster than rats given initial single-stimulus training with one light intensity. Third, "transfer of stimulus control" can be said to have occurred when prior training with stimuli in

This research was supported by the School of Psychology, University of New South Wales, and the Australian Research Grants Scheme (A27815154). The authors express their gratitude to Louise Hyman and Maria Quinn for their aid in collecting the data and to Jean Jensen for preparation of the manuscript. Requests for reprints should be sent to E. James Kehoe, School of Psychology, University of New South Wales, P.O. Box 1, Kensington, N.S.W. 2033, Australia. one modality produces sharper generalization gradients around the training stimulus in the second modality. For example, Thomas, Freeman, Svinicki, Burr, and Lyons (1970, Experiment 5) found that training pigeons on a floor-tilt discrimination while a green light continuously illuminated the response key sharpened generalization gradients along the color dimension (cf. Honig, 1969; Reinhold \& Perkins, 1955).

Although extradimensional transfer may appear to arise from a global change in the animal's learning and/or performance abilities, experimentation has revealed that there are boundaries to the extent of transfer. Among other things, transfer is modulated in crucial, but poorly understood, ways by similarities between the successive tasks in the structure of their respective stimulus-reinforcer and response-reinforcer contingencies (Harlow, 1949; Thomas, 1970). Extradimensional transfer has been repeatedly demonstrated between instrumental discrimination tasks (e.g., Frieman \& Goyette, 1973; Thomas et al., 1971). However, dramatic reductions in the magnitude of transfer have been obtained when the change in stimuli is accompanied by changes in the structure of response-reinforcer relations. For example, Rodgers and Thomas (1982) eliminated substantial general transfer between line tilt and color dimensions in pigeons by changing the task from a left/right choice procedure to a go/nogo discrimination (and vice versa). Similarly, investigations using extended series of instrumental discrimination problems ("learning sets") have yielded both positive and negative transfer, depending on the congruence of stimulus-response-reinforcer contingencies across tasks (e.g., Behar \& LeBedda, 1974; Harlow, 1949; Ricciardi \& Treichler, 1970; Riopelle, 1953). 
The correlated nature of stimulus-reinforcer and response-reinforcer relations in instrumental discrimination tasks makes it difficult to isolate the role of each relation in both producing and limiting extradimensional transfer. However, extradimensional transfer has been obtained recently on the basis of Pavlovian stimulusreinforcer relations. For example, Westbrook and Homewood (1982) found that toxicosis conditioning with one flavor (e.g., sucrose) facilitated subsequent acquisition of an aversion to a new flavor (e.g., salt). Similarly, Kehoe and Holt (1984) found general transfer from pairings of a CS (e.g., light) with a shock unconditioned stimulus (US) to pairings of a CS in another modality (e.g., tone) with the same US in classical conditioning of the rabbit's nictitating membrane response (NMR). Furthermore, counterbalancing the order of the CSs revealed that the transfer between visual and auditory CSs was symmetric in magnitude. Because a clear delineation of the boundaries of extradimensional transfer would provide insight into its mechanisms, the present experiments further examined the role of stimulus-reinforcer relations in extradimensional transfer. Specifically, Experiment 1 examined transfer from initial training with a single visual CS to subsequent auditory discrimination training, and Experiment 2 examined transfer from visual discrimination training to auditory discrimination training.

\section{EXPERIMENT 1}

The magnitude of transfer from a stimulus-reinforcer relation to either discrimination learning or to its constituent stimulus-reinforcer relations has not been explored in classical conditioning. In research concerning extradimensional transfer between instrumental discriminations, initial training with a single stimulus has typically been used as a baseline condition for assessing subsequent general transfer to discrimination learning and/or transfer of stimulus control. Typically, initial single-stimulus training produces less rapid discrimination learning and less stimulus control than initial discrimination training (Eck, Noel, \& Thomas, 1969; Honig, 1969, p. 39; Thomas et al., 1970, Experiment 5, 1971). However, those experiments lacked a "no-learning" condition which would act as a baseline for determining whether or not initial single-stimulus training facilitates (1) the rate of response acquisition to the subsequent reinforced stimulus and/or (2) the rate of discrimination learning between the reinforced and nonreinforced stimuli. Consequently, the present experiment examined the effects of initial CSUS training on subsequent discrimination training relative to a "no-learning" baseline condition.

The animals were given initial CS-US training with an intermittent light CS (flashing houselight) at a 400-msec CS-US interval. Subsequently, they were given discrimination training between an intermittent tone and a continuous tone. As a baseline for the detection of transfer effects, a control group received initial training with the light CS at a 3,000-msec CS-US interval. The baseline condition fulfilled two criteria: (1) the same exposure to the apparatus, CS, and US as received by the experimental group, and (2) minimal excitatory or inhibitory conditioning during the initial phase (Kehoe \& Holt, 1984; Kehoe, Morrow, \& Holt, 1984). In previous research, this control condition has proved to be a conservative baseline for positive transfer in that exposure to a long CSUS interval yields slight, but not significant, transfer relative to a more conventional "rest" control that received exposure to just the apparatus (Kehoe \& Holt, 1984, Experiment 2). During auditory discrimination training, three measures of transfer were obtained: (1) "immediate transfer," as measured by the level of responding on the first presentations of the auditory CSs, (2) "general transfer between CSs,' ' as measured by the rate of CR acquisition to $\mathrm{CS}+$, and (3) "general transfer of discrimination learning," as measured by the level of differentiation between $\mathrm{CS}+$ and $\mathrm{CS}-$.

\section{Method}

Subjects. The subjects were 32 naive female albino rabbits (Oryctolagus cuniculus). On arrival, each rabbit was 70-80 days old and weighed approximately $1.5 \mathrm{~kg}$. All rabbits had free access to food and water in their home cages.

Apparatus. The apparatus and recording procedure for the nictitating membrane response (NMR) were patterned after those of Gormezano (1966) and are described in detail by Kehoe, Feyer, and Moses (1981). In brief, the rabbits were restrained in Perspex boxes and trained individually in eight sound-attenuating, ventilated conditioning chambers. A speaker was mounted at a $45^{\circ}$ angle $8 \mathrm{~cm}$ anterior to and $16 \mathrm{~cm}$ above the subject's head. The speaker provided an auditory stimulus, which was a 1000- $\mathrm{Hz}, 93-\mathrm{dB}$ (SPL) tone. To provide distinctive CSs for auditory discrimination training, the tone was presented either continuously for $800 \mathrm{msec}$ or intermittently ( $30 \mathrm{msec}$ on $/ 20 \mathrm{msec}$ off) for $800 \mathrm{msec}$. Both tones were superimposed upon the constant background noise of the ventilation fans $(82 \mathrm{~dB})$. An $8-\mathrm{W}$ frosted neon light tube, which was mounted $4 \mathrm{~cm}$ above the speaker provided both the houselight and an intermittent visual $\mathrm{CS}$, which was a flashing of the light $(30 \mathrm{msec}$ off $/ 20 \mathrm{msec}$ on) for $400 \mathrm{msec}$. The US was a $50-\mathrm{msec}, 3-\mathrm{mA}, 50-$ $\mathrm{Hz}$ ac shock delivered via stainless steel Autoclip wound clips positioned $10 \mathrm{~mm}$ apart and $15 \mathrm{~mm}$ posterior to the dorsal canthus of the right eye. The sequence and timing of stimulus events was controlled by an Apple II computer equipped with interfaces and software developed by Scandrett and Gormezano (1980).

Each rabbit's right external eyelids were held open by No. 3 tailor hooks mounted on a Velcro strap fitted about the head. A muzzlelike headset supported a photosensitive transducer for monitoring movements of the nictitating membrane. A small hook was attached to a loop of silk sutured in the nictitating membrane of the rabbit's right eye. The hook was connected by a thread to one end of an L-shaped piano wire lever, which mechanically transmitted the movement of the nictitating membrane to the transducer. Inside the transducer, movement of the lever rotated a disk of polarized filter, which was interposed between a light-emitting diode and a phototransistor covered by a fixed polarized filter. Thus, rotation of the disk produced changes in the intensity of the light reaching the transistor through the fixed filter. The signal from the transistor was amplified and transmitted to an analog/digital converter attached to the computer.

Procedure. All rabbits received 1 day of preparation, 1 day of adaptation, 3 days of initial acquisition training with the intermittent light $C S$, and 5 days of auditory discrimination training. On the preparation day, hair surrounding the rabbit's right eye was removed, and a small loop of silk ( 000 Dynex) was sutured into the 
nictitating membrane. On the adaptation day, the animals were placed in the conditioning apparatus for $2 \mathrm{~h}$, but neither the CSs nor the US was presented. The animals were assigned randomly to two groups $(n=16)$. Group L400 received 3 days of training with the intermittent light at a 400 -msec CS-US interval, and Group L3000 received training with the intermittent light at a 3,000-msec CS-US interval. Each day consisted of 108 CS-US trials, and the mean intertrial interval (ITI) was $60 \mathrm{sec}$ (range 40-80 sec). At the end of the last day of training with the light, both groups received four unreinforced presentations of the intermittent tone intermixed with four of the continuous tone under the same ITIs as for the previous light trials. These presentations were a test for immediate transfer of responding to the auditory CSs

Following light training, each group was subdivided into two further groups $(n=8)$ for the 5 days of auditory discrimination training. On each day of discrimination training, Groups L400-B+ and L3000-B+ received 120 trials, which consisted of 60 reinforced trials with the intermittent ("beeping') tone as CS+ and 60 unreinforced trials with the continuous tone as CS - . Groups L400$\mathrm{T}+$ and $\mathrm{L} 3000-\mathrm{T}+$ received the same schedule, but the continuous tone was CS+ and the intermittent tone was CS-. The schedule of trials was arranged so that not more than three CS+ or three CS - trials were presented consecutively. On CS + trials, the CSUS interval was $800 \mathrm{msec}$, a value that produces a moderate rate of $C R$ acquisition and thus leaves room for the detection of either positive or negative transfer. The mean ITI was $60 \mathrm{sec}$.

A conditioned response (CR) was defined as any extension of the nictitating membrane exceeding $.5 \mathrm{~mm}$ which occurred following the onset of the CS and prior to the onset of the US. Planned, orthogonal contrasts were used to analyze the data (Hays, 1969, p. 482). The rejection level was set according to a Type I error rate of .05 .

\section{Results}

Figure 1 shows acquisition of CRs to the visual CS plotted as mean percent CRs across blocks of trials for Groups LA00 and L3000. The curves clearly indicate that the 400msec CS-US interval produced faster and higher levels of CR acquisition than the 3,000-msec CS-US interval. Responding in Group LA00 attained terminal levels exceeding $90 \%$ CRs, whereas responding in Group L3000 never rose above $10 \%$ CRs. Statistical analysis confirmed

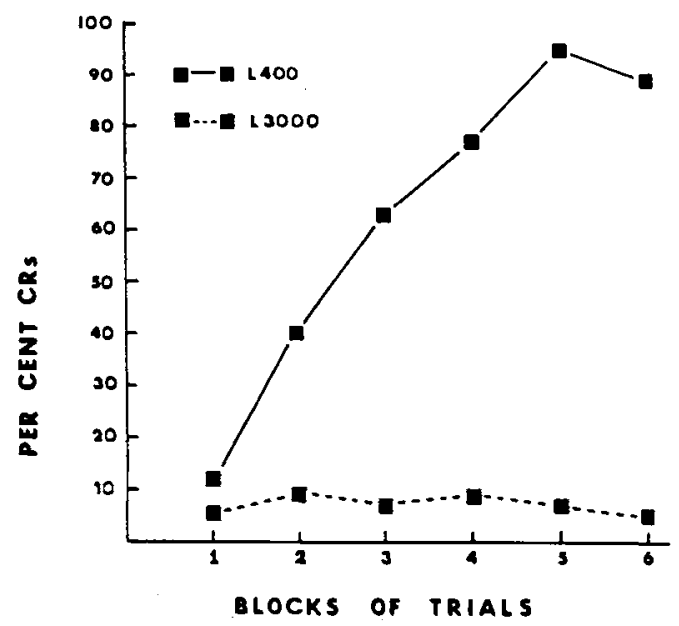

Figure 1. Acquisition of CRs to the visual CS plotted as mean percent CRs across blocks of 54 trials for Groups L400 and L3000 in Stage 1 of Experiment 1. that there was a significant main effect of CS-US interval $[F(1,28)=136.29]$ which interacted with the linear trend over blocks of trials $[F(1,28)=162.11]$.

The tests for immediate transfer from the visual CS to the auditory stimuli conducted at the end of initial training revealed that no responses were made to the presentations of the auditory stimuli. Similarly, examination of responding on the first four trials of auditory discrimination training showed that only $5 \%$ CRs were made to the auditory stimuli. These levels of responding to auditory stimuli are consistent with the rate of "spontaneous responding" obtained with CS-alone presentations in the rabbit NMR preparation (cf. Gormezano, Kehoe, \& Marshall, 1983). Thus, reinforced training with the intermittent light did not appear to result in immediate transfer to the two auditory stimuli (cf. Kehoe \& Holt, 1984).

In Figure 2, Panel a shows the mean percent CRs made by each group to its auditory CS+ across blocks of trials and Panel $b$ shows the mean percent CRs made by each group to its auditory CS- across blocks of trials. Examination of both panels in Figure 2 reveals that Group L400 showed substantially faster $\mathrm{CR}$ acquisition than Group L3000 over the first five blocks to both the CS+ and CS- . This observation was confirmed by a significant difference between Group L400 and Group L3000 in overall percent CRs to the auditory stimuli $[F(1,28)$ $=11.37]$, which interacted with the linear trend across blocks of trials $[F(1,28)=6.64]$. Thus, prior conditioning of the visual CS facilitated CR acquisition to the auditory CSs.

Although Group L 400 showed faster CR acquisition to the auditory CSs than Group L3000, the two groups did not appear to differ in their level of discriminative responding to $\mathrm{CS}+$ and $\mathrm{CS}-$. Both groups showed discrimination learning, which was confirmed by a significant difference between the level of responding to CS+ and CS $-[F(1,28)=107.42]$ which interacted with the linear trend over training trials $[F(1,28)=38.96]$. However, there were no interactions with the groups factor, $L 400$ versus $L 3000$. The course of auditory discrimination learning can be more clearly seen in Figure 3, which shows the discrimination ratios for each group across blocks of trials. A discrimination ratio was calculated for each subject for each block of trials by dividing the percent CRs to the CS+ by the sum of percent CRs to the CS+ and the CS-. Examination of Figure 3 reveals that Group L 400 showed a modest level of discrimination, which hovered around a ratio of .65 for the entirety of auditory discrimination training, while Group $\mathrm{L} 3000$ showed a rise in discrimination performance from virtually chance-level performance to a terminal ratio in excess of .70. However, the apparent differences between the two groups failed to attain statistical significance.

Further inspection of Figure 2 reveals that the temporal pattern of the auditory stimuli had some influence on responding in Group L400 but not L3000. An analysis of Group L400's data showed that animals trained with 

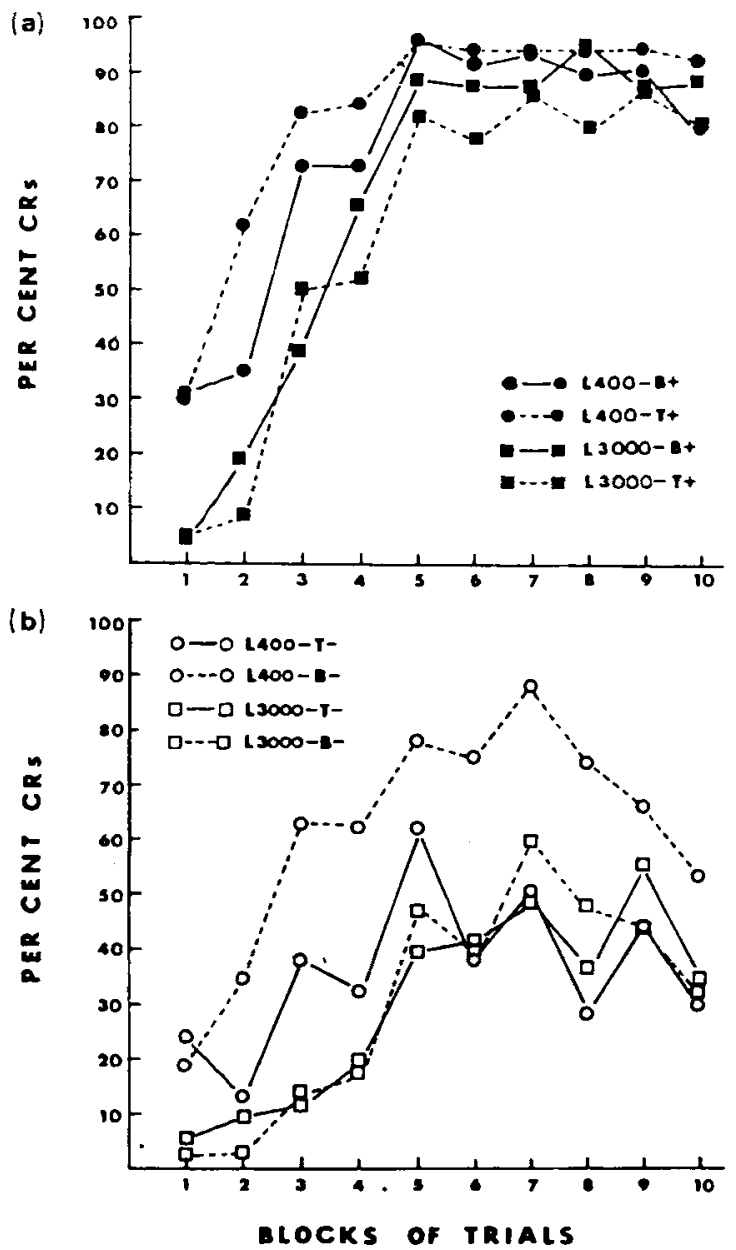

Figure 2. Mean percent CRs made to the auditory CS+ (Panel a) and CS- (Panel b) plotted across blocks of 30 trials for Groups L 400 and $\mathbf{L 3 O O O}$ in Stage 2 of Experiment 1.

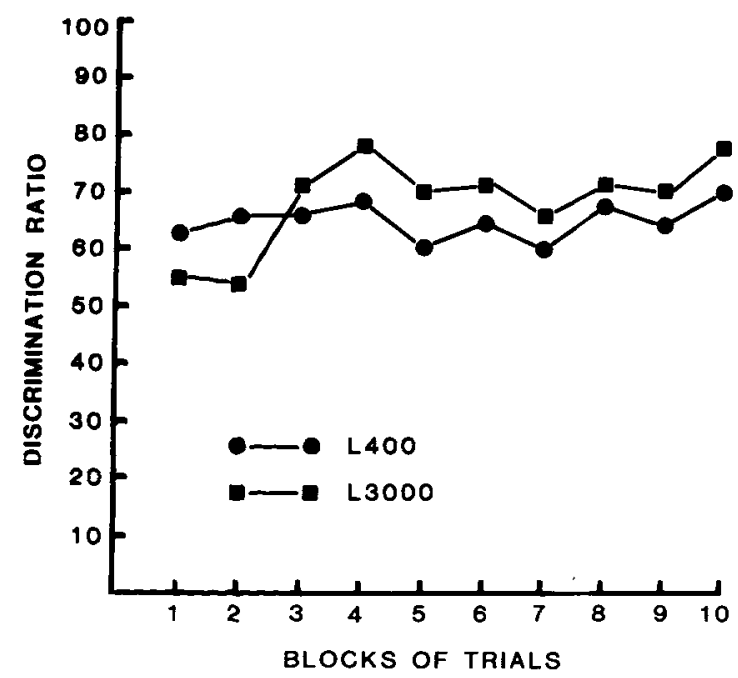

Figure 3. Mean discrimination ratios plotted across blocks of 30 trials for Groups $\mathrm{LAOO}$ and $\mathrm{L3000}$ in Stage 2 of Experiment 1. the continuous tone as $\mathrm{CS}+$ and the intermittent tone as CS- showed a higher overall level of responding than the animals trained with the intermittent tone as CS+ and the continuous tone as CS- $[F(1,28)=5.26]$. The difference between the two subgroups was particularly pronounced with respect to $C S-[F(1,28)=4.49]$. Thus, the animals that received an auditory $\mathrm{CS}+$ (continuous tone) that was not congruent with the temporal pattern of the initial, intermittent visual CS showed a higher level of responding than the animals for which the auditory CS+ (intermittent tone) was identical in temporal pattern to the visual CS.

\section{Discussion}

The present experiment demonstrated that singlestimulus conditioning with the visual CS in Group L400 facilitated subsequent $\mathrm{CR}$ acquisition to the auditory CS+ and also the auditory CS- - Thus, the subjects appeared to have, first, encoded the stimulus-reinforcer relation in initial CS-US training and, second, detected the corresponding relation between the CS+ and the US, which was embedded in the auditory discrimination task. Thus, the animals do not appear to encode the discrimination task as a whole, at least not to the exclusion of encoding its constituent stimulus-reinforcer relations. Moreover, the level of responding to the auditory $\mathrm{CS}+$ and CS- rose in a parallel fashion in Group L400 relative to Group L3000. Thus, the initial training with a single stimulus-reinforcer relation failed to facilitate subsequent discrimination learning. In summary, the pattern of results suggests that general transfer across CS modalities is specific to their common stimulus-reinforcer relations.

\section{EXPERIMENT 2}

The present experiment examined cross-modal transfer from a visual discrimination task to an auditory discrimination task. The results of Experiment 1 showed that CS-US training with a visual CS facilitated overall $C R$ acquisition to the auditory CSs irrespective of the requirements for discrimination learning. However, in the instrumental conditioning literature, prior discrimination training between two values of a stimulus dimension has been found to facilitate discrimination learning along another stimulus dimension (e.g., Thomas et al., 1971). Accordingly, we wished to determine whether the two types of transfer could be superimposed. To this end, the animals received one of three initial training conditions: (1) Group TD received "true discrimination" training in which the intermittent light was CS+ and a continuous visual stimulus (houselight off) was CS- . (2) Group PD was given "pseudodiscrimination" training in which the two visual CSs were each followed by the US on a $50 \%$ schedule. (3) Group LD received "long-interval discrimination" training in which the intermittent light was followed by the US at a 3,000-msec CS-US interval and the continuous light-off CS was never followed by the US. Subsequently, all groups of rabbits were transferred to the auditory discrimination learning task. In terms of the 
formal structure of the tasks, the TD condition permitted cross-modal transfer based on both the CS-US relations and the discrimination contingencies common to the successive tasks. The PD condition permitted transfer based on CS-US relations but prevented transfer based on discrimination contingencies. Thus, Group PD provided a baseline for the detection of transfer of discrimination learning (Honig, 1969; Thomas, 1970). Group LD prevented transfer based on a prior contiguous CS-US relation but allowed for latent discrimination learning. Thus, Group LD acted as a baseline for the detection of general transfer based on the contiguous CS-US relation in Group TD's initial training.

\section{Method}

The subjects were 48 naive female albino rabbits, $60-70$ days old and weighing about $1.5 \mathrm{~kg}$ on arrival. The rabbits had free access to food and water in their home cages.

Except where noted, the procedures and apparatus were identical to those used in Experiment 1. All rabbits received 1 day of preparation, 1 day of adaptation, 9 days of visual discrimination training, and 6 days of auditory discrimination training. The rabbits were assigned randomly to three groups $(n=16)$. A truediscrimination group (TD) received training in which CS+ was the flashing of the houselight for $800 \mathrm{msec}$ and CS- was the houselight's being switched off for a duration of $800 \mathrm{msec}$. A pseudodiscrimination group (PD) received the same visual stimuli, but each CS was followed by the US on $50 \%$ of its trials. In both Group.TD and Group PD, the CS-US interval on reinforced trials was $800 \mathrm{msec}$. A long-interval discrimination group (LD) received "discrimination training"' like that of Group TD, but the intermittent light CS+ was followed by the US at a CS-US interval of $3,000 \mathrm{msec}$. All groups received 72 trials per day, consisting of 36 trials with the intermittent light CS and 36 trials with the lightoff CS. Not more than three of the same type of CS were presented consecutively.

Following visual discrimination training, the three groups were subdivided into six groups $(n=8)$ for auditory discrimination training. On each day of training, Groups TD-B+, PD-B+, and LD$\mathrm{B}+$ received 72 trials, consisting of 36 reinforced presentations of the intermittent tone (CS+) and 36 unreinforced presentations of the continuous tone (CS-). Groups TD-T+, PD-T+, and LD-T+ received the same schedule, but the continuous tone was CS+ and the intermittent tone was CS-. The duration of both stimuli was $800 \mathrm{msec}$, and the CS-US interval was $800 \mathrm{msec}$.

\section{Results and Discussion}

Figure 4 shows the acquisition of CRs to the visual CSs plotted as mean percent CRs across days for Groups TD (Panel a), PD (Panel b), and LD (Panel c). Examination of Figure 4 reveals that Group TD showed substantial CR acquisition to CS+ and learned to discriminate between the two visual stimuli. By the last day of visual discrimination training, Group TD showed $85 \%$ CRs to the intermittent light CS+ and $22 \% \mathrm{CRs}$ to the light-off CS- . In contrast, Group PD showed appreciable CR acquisition to both CSs, reaching terminal levels of $75 \%$ CRs to the intermittent light CS and 50\% CRs to the light-off CS. The higher level of responding to the intermittent light in Group PD would appear to arise from the dynamogenic intensive effect of intermittent stimuli relative to continuous stimuli (Gormezano, 1972). Finally, Group LD never showed more than $20 \%$ CRs to either the intermittent light
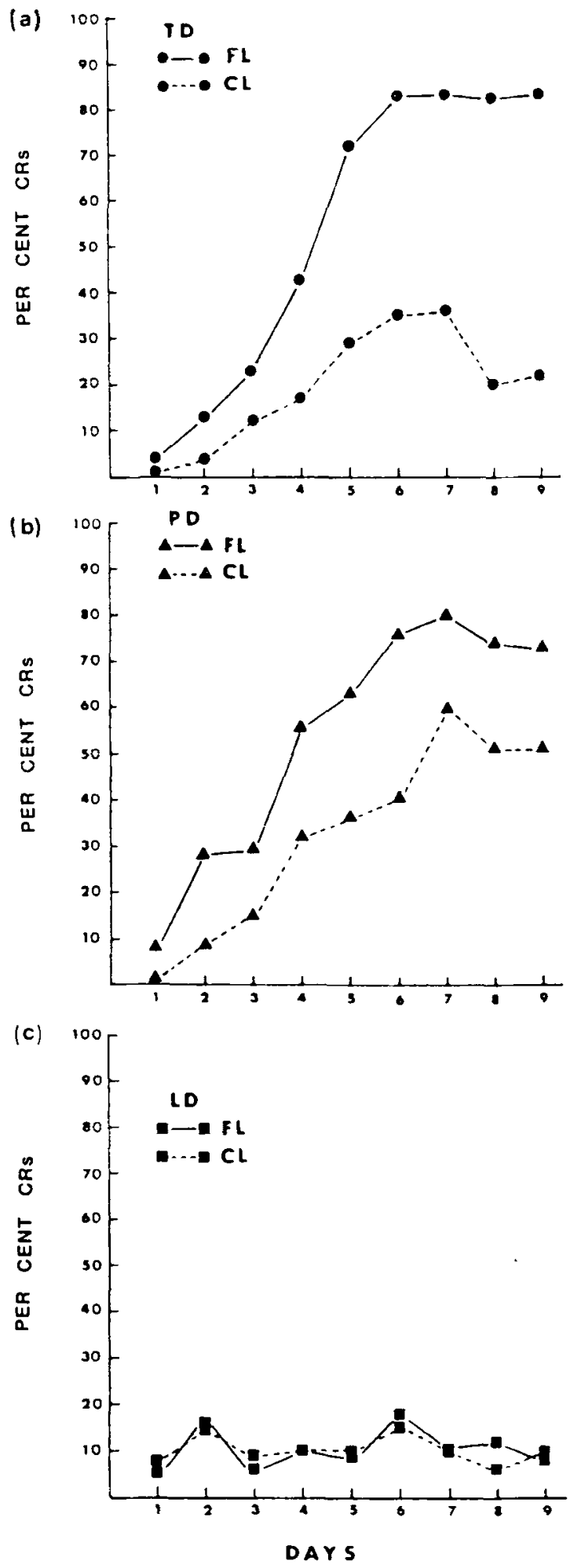

Figure 4. Acquisition of CRs to the flashing light (FL) and the continuous light-off (CL) plotted as mean percent CRs across days (60-trial blocks) for Groups TD (true discrimination, Panel a), PD (pseudodiscrimination, Panel b), and LD (long-interval discrimination, Panel c) in Stage 1 of Experiment 2. 
$\mathrm{CS}+$ or the light-off $\mathrm{CS}-$. These observations were supported by statistical comparisons, which revealed that Groups TD and PD both showed a higher overall level of responding than Group LD $[F s(1,45)=27.27$ and 43.34, respectively]. Groups TD and PD did not significantly differ in the overall level of responding $[F(1,45)$ $=1.85, \mathrm{p}>.05 \mathrm{]}$, but with respect to discrimination learning, Group TD showed a greater difference between responding to the intermittent light CS and light-off CS than did Group PD $[F(1,45)=16.22]$.

Examination of the first four trials of auditory discrimination training revealed no evidence of immediate transfer to the two auditory CSs. Groups TD, PD, and LD showed mean levels of $9 \%, 9 \%$, and $6 \%$ CRs, respectively.

Figure 5 shows the acquisition of CRs to the auditory CS+ (Panel a) and CS- (Panel b) across blocks of trials
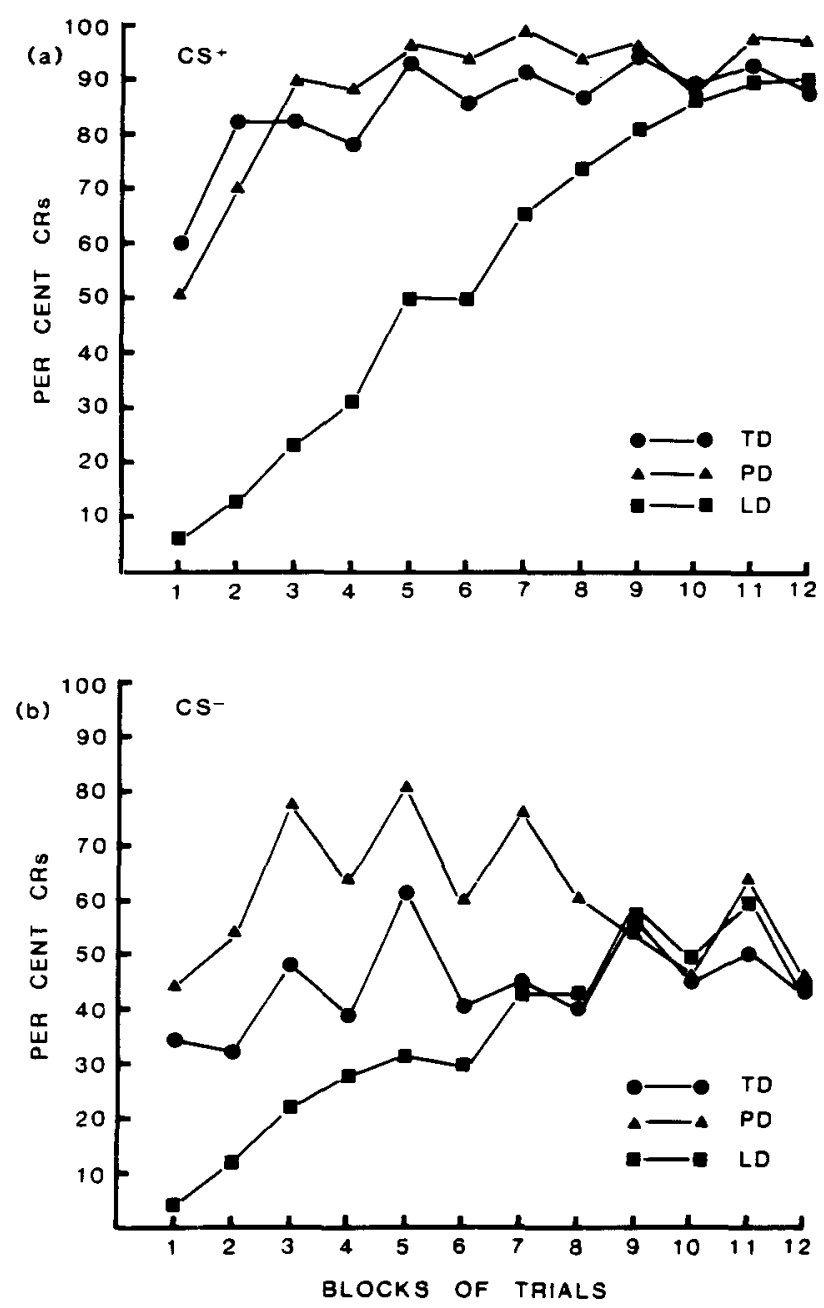

Figure 5. Acquisition of CRs to the auditory CS+ (Panel a) and CS- (Panel b) plotted across blocks of 30 trials for Groups TD (true discrimination), PD (pseudodiscrimination), and LD (long-interval discrimination) in Stage 2 of Experiment 2. for Groups TD, PD, and LD. Groups TD and PD showed more rapid CR acquisition to both CSs than did Group LD $[F s(1,42)=29.18$ and 33.69 , respectively]. Groups TD and PD appeared to have a similar overall rate of CR acquisition $(F<1)$. For example, in the first block of trials, Group TD showed a mean level of $60 \% \mathrm{CRs}$ to $\mathrm{CS}+$ and $34 \%$ CRs to CS-; Group PD showed $50 \%$ CRs to CS+ and $44 \%$ CRs to CS-; and Group LD showed only $6 \%$ CRs to CS+ and $4 \%$ CRs to CS-. Thus, the facilitation of overall CR acquisition in Groups TD and PD confirmed that the animals are able to extract contiguous CS-US relations embedded in more complex schedules and to detect the corresponding relations in subsequent discrimination training. The transfer within Group TD is not so surprising, since the two tasks were identical except for the change in CS modality. However, in the case of Group PD, the initial pseudodiscrimination procedure contained two partially reinforced CS-US relations, which differed dramatically from the subsequent discrimination procedure.

Although Groups TD and PD did not appear to differ in their overall level of responding, Group TD showed a greater difference between the levels of responding to CS+ and CS- than did either Group PD $[\mathrm{F}(1,42)=$ 4.57] or Group LD [F(1,42) = 14.18]. Furthermore, Group PD and Group LD failed to differ significantly in their discriminative performance $[\mathrm{F}(1,42)=2.65, \mathrm{p}>$ $.05]$. The course of auditory discrimination learning can be more clearly seen in Figure 6, which shows the discrimination ratios for each group as a function of blocks of trials. Inspection of Figure 6 shows that, in the first block of auditory discrimination training, Group TD attained a modest level of discrimination performance (.73), Group PD performed slightly above chance level (.54), and Group LD performed slightly below chance level (.41). By the fifth block of trials, all groups had converged to an asymptotic level around .75. Statistical analysis of the discrimination ratios revealed the same pattern of results as the analysis of the percent CR data. Thus, in addition to the facilitation of overall $C R$ acquisition based on previous CS-US relations, the results of Group TD indicate that prior visual discrimination training facilitated subsequent auditory discrimination learning.

Although there was substantial general transfer in the present experiment, there was no evidence to suggest that cross-modal transfer was facilitated by a common temporal pattern in stimuli across tasks (cf. Seraganian \& Popova, 1976; Yehle \& Ward, 1969). Within Group TD, the rate of discrimination learning appeared to be the same whether or not the reinforcement contingencies for the intermittent tone and continuous tone were congruent with previous assignment of the intermittent light as CS+ and the continuous light-off as CS-. Statistical analysis failed to reveal any significant differences between Groups TD, $P D$, and $L D$ that interacted with the stimulus assignments in auditory discrimination training. However, there was a main effect similar to that seen in Group L400 of Experiment 1; animals trained with the continuous tone as 


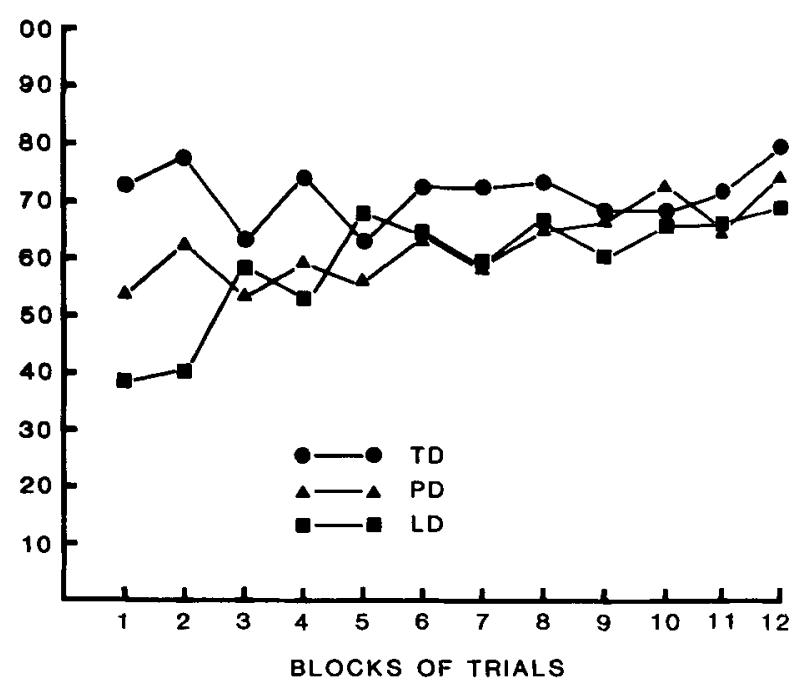

Figure 6. Mean discrimination ratios plotted across blocks of 30 trials for Groups TD (true discrimination), PD (pseudodiscrimination), and LD (long-interval discrimination) in Stage 2 of Experiment 2.

$\mathrm{CS}+$ and the intermittent tone as CS- showed levels of responding to both stimuli that were 12 percentage points higher than did the animals for which the intermittent tone was CS + and the continuous tone was CS- $[\mathrm{F}(1,42)=$ 5.35].

Although the similarities in the temporal patterns of the stimuli failed to alter transfer, the animals were clearly sensitive to the temporal patterns of both the visual and auditory stimuli. In particular, Group TD showed discrimination learning in both the visual and auditory modalities on the basis of differences between the temporal patterns of CS + and CS - . However, the basis for those discriminations may not have been the difference in temporal patterns of the stimuli as such. Instead, the animals may have been sensitive only to the differences in the intensive effects of the intermittent versus continuous stimuli. Converging evidence for the different intensive effects of the intermittent and continuous stimuli can be seen in Group PD's higher level of responding to the intermittent light relative to the continuous light. On the basis of previous demonstrations of immediate cross-modal transfer (e.g., Seraganian \& Popova, 1976; Yehle \& Ward, 1969), immediate cross-modal transfer might have been obtained had the frequency of stimulus pulses in the intermittent stimuli been lower.

\section{GENERAL DISCUSSION}

The present experiments yielded two major findings. First, CS-US training with one or more visual CSs facilitated the overall rate of CR acquisition to subsequent auditory CSs, irrespective of the requirements for discrimination learning. In Experiment 1, the contiguous CS-US relation in initial visual training facilitated subsequent responding to both the auditory CS+ and CS - . Similarly, in Experiment 2, initial reinforced training with the visual $\mathrm{CS}+$ in the TD group and the partial reinforcement of the two visual CS-US relations in the PD group resulted in substantial transfer to both auditory CSs. Second, TD training in Experiment 2 facilitated subsequent discrimination learning relative to initial PD training. Thus, in the TD condition, two forms of general transfer were superimposed on one another.

The demonstration that initial TD training in one modality enhances subsequent discrimination learning in another modality duplicates corresponding findings in the instrumental conditioning literature (e.g., Thomas, 1970; Thomas et al., 1971). Furthermore, a comparison between the discrimination ratios on the first block of trials across Experiments 1 and 2 reveals that Group TD showed better auditory discrimination (.73) than did Group L400 (.62), which, in turn, showed discrimination that was superior to that of Group PD (.54). This ordering of the effects of initial TD, single CS, and PD training agrees with the findings of Thomas and his associates. This comparison also suggests that initial PD training may have yielded some negative transfer across modalities with respect to discrimination training.

The present experiments have extended previous findings by demonstrating that the contiguous CS-US relations common to the TD, single CS, and PD conditions are sufficient to produce transfer across modalities not simply to other isolated CS-US relations but also to contiguous CS-US relations embedded in more complex discrimination tasks. In the particular case of Group PD, the animals showed that they could encode CS-US relations from initial partial reinforcement training and detect the consistent contiguous CS-US relation in subsequent discrimination training.

In searching for the sources of general transfer, two candidates would appear to be unlikely: (1) General transfer might simply result from adaptation to handling, the apparatus, and/or stimuli. However, several demonstrations of general transfer with the NMR and other preparations have included a control condition with the same exposure to the apparatus, initial CS, and the US as the transfer condition (Kehoe \& Holt, 1984; Thomas et al., 1971; Westbrook \& Homewood, 1982). In the present experiments, the only difference between Groups L400 and L3000 in Experiment 1 and between Groups TD and LD in Experiment 2 was the CS-US interval in initial training. (2) General transfer may arise from stimulus generalization from the initial CS to the new CS. However, the aggregate of data collected in our laboratory has revealed no statistical evidence for immediate transfer across CS modalities in the rabbit NMR preparation. In the transfer experiments conducted so far, immediate transfer has been assessed on the first four presentations of the new CS in transfer training. Thus, any individual animal could show $0,1,2,3$, or 4 responses on the initial CS presentations in the second modality. Including subjects from the present experiments, $106 \mathrm{ex}$ perimental subjects have received prior training with a 
$\mathrm{CS}$ at a relatively short CS-US interval, and 98 control subjects have received either no prior training or prior exposure to a long CS-US interval. Among the experimental subjects, $77 \%, 15 \%, 4 \%, 1 \%$, and $3 \%$ showed 0,1 , 2,3 , and 4 responses, respectively. Similarly, among the control subjects, $83 \%, 11 \%, 5 \%, 0 \%$, and $1 \%$ showed $0,1,2,3$, and 4 responses, respectively. Any apparent difference between the two distributions failed to attain statistical significance $\left[\chi^{2}(4)=2.80, p>.50\right]$. Given the large number of subjects and the corresponding power to detect any differences between the experimental and control conditions, it would seem unlikely that there was even much subthreshold generalization. Certainly, the present results do not indicate that overt stimulus generalization is a necessary precursor to general transfer.

More plausible accounts of extradimensional transfer can be found in the instrumental discrimination literature. There are two types of accounts for extradimensional transfer between instrumental discriminations: stimuluscentered accounts and response-centered accounts. Stimulus-centered accounts have contended that the stimulus-reinforcer relations in initial discrimination training either produce "general attention" to all other stimulus differences (Thomas, 1970, p. 344) or neutralize interference by incidental stimuli common to initial and subsequent training (Mackintosh, 1977; Seraganian, 1979). Likewise, response-centered accounts have contended that initial training either enhances specific choice response strategies (e.g., Behar \& LeBedda, 1974; Levine, 1959; Rodgers \& Thomas, 1982) or neutralizes inappropriate strategies (Harlow, 1959). On the one hand, stimulus-centered theories offer plausible accounts of the extradimensional transfer observed in the present classical conditioning experiments. On the other hand, the response-centered theories fall outside the present discussion, because they are intended for transfer across instrumental procedures, particularly across different simultaneous discrimination procedures.

Thomas's (1970) stimulus-centered theory contends that extradimensional transfer results from a superordinate learning process. Specifically, Thomas (1970) explains general transfer between discrimination tasks by contending that the animal acquires not only a specific discrimination during initial training, but also a "general attentiveness" to stimulus differences. Subsequently, this acquired disposition facilitates the acquisition of differential responding in other discrimination learning tasks. Within the present results, the facilitation of discrimination learning in Group TD of Experiment 2 is consistent with the general attention theory. Furthermore, general attention theory may be extended to account for the facilitation of overall CR acquisition based on contiguous CSUS relations, as seen in Group L400 of Experiment 1 and Groups TD and PD of Experiment 2. Extradimensional transfer between CS-US relations could be assimilated to transfer between discriminations by assuming that training with a discrete CS-US relation entails a discrimination between a compound stimulus (CS + background) as opposed to the background stimuli present during the intertrial interval. Accordingly, such initial training with a simple CS-US relation would enhance "general attention" to subsequent differences between other discrete CSs and background stimuli. However, a discrimination between a CS and background stimuli does not appear equivalent to a discrimination between two explicit CSs insofar as general transfer is concerned. Otherwise, any CS-US training, as in Group L400, should have facilitated not just overall CR acquisition but also discrimination between $\mathrm{CS}+$ and $\mathrm{CS}-$. Hence, there may be different levels of encoding in relation to the types of discriminations required in initial training.

The first type of stimulus-centered theories assumes that the animal acquires a sensitivity to the structural relations between stimuli and reinforcers, whereas the second type of stimulus-centered theories is purely associative and does not postulate any superordinate learning process. According to these theories, general transfer arises indirectly from the neutralization of background stimuli that would otherwise compete with the discrete CS for the animal's processing resources (Kehoe \& Holt, 1984; Mackintosh, 1977; Seraganian, 1979; Westbrook \& Homewood, 1982). Presumably, initial exposure to the contiguous CSUS relation not only increases the associative strength of the CS but also lowers the associability of the less predictive background stimuli. On the one hand, neutralization of background stimuli can readily account for the general transfer between CS-US relations. However, it is less easy to see how discrimination training between two visual stimuli in Group TD could have further neutralized the background stimuli. In order to make a neutralization account more plausible, it would be necessary to identify stimulus dimensions that are common to both the auditory and visual CSs but that are irrelevant to the visual and auditory discrimination tasks. If such dimensions do exist, then it could be argued that initial discrimination training in one modality neutralizes the irrelevant dimensions that would otherwise interfere with subsequent acquisition of the auditory discrimination (cf. Mackintosh, 1977).

Regardless of the underlying sources of general transfer, it is clear from the present experiments that general transfer empirically depends on the stimulus-reinforcer relations during initial training: contiguous CS-US relations in initial training facilitate the acquisition based on subsequent contiguous CS-US relations even if embedded in otherwise distinct overall task structures. Likewise, explicit discriminations along a dimension within a single modality facilitate subsequent acquisition of discriminations along other dimensions. It remains to be determined whether transfer between discriminations relies on (1) an encoding of the discrimination task as a whole which is separate from the CS-US relation (cf. Thomas, 1970), or (2) the summation of two encodings, one for the contiguous CS-US relation for CS+ and one for the CS-alone presentations of CS- (cf. Behar \& LeBedda, 1974). 


\section{REFERENCES}

BEHAR, I., \& LEBEDDA, J. M. (1974). Effects of differential pretraining on learning-sete formation. Journal of Comparative and Physiological Psychology, 82, 277-283.

Eck, K. O., Noel, R. C., \& Thomas, D. R. (1969). Discrimination learning as a function of prior discrimination and non-differential training. Journal of Experimental Psychology, 82, 156-162.

Frieman, J., \& Goyette, C. H. (1973). Transfer of training across stimulus modality and response class. Journal of Experimental Psychology, 97, 235-241

Gormezano, I. (1966). Classical conditioning. In J. B. Sidowski (Ed.), Experimental methods and instrumentation in psychology (pp. 385420). New York: McGraw-Hill.

Gormezano, I. (1972). Investigations of defense and reward conditioning in the rabbit. In A. H. Black \& W. F. Prokasy (Eds.), Clas sical conditioning II: Current research and theory (pp. 151-181). New York: Appleton-Century-Crofts

Gormezano, I., Kehoe, E. J., \& Marshall, B. S. (1983). Twenty years of classical conditioning with the rabbit. In J. M. Sprague \& A. N. Epstein (Eds.), Progress in psychobiology and physiological psychology (Vol. 10, pp. 197-275). New York: Academic Press.

Harlow, H. F. (1949). The formation of learning sets. Psychological Review, 56, 51-65.

HaRLow, H. F. (1959). Learning set and error factor theory. In S. Koch (Ed.), Psychology: A study of a science (Vol. 2, pp. 492-537). New York: McGraw-Hill.

Hays, W. L. (1969). Statistics. London: Holt, Reinhart, \& Winston.

HoNiG, W. K. (1969). Attentional factors governing the slope of the generalization gradient. In R. M. Gilbert \& N. S. Sutherland (Eds.) Animal discrimination learning (pp. 35-62). London: Academic Press

Kehoe, E. J., Feyer, A., \& Moses, J. L. (1981). Second-order conditioning of the rabbit's nictitating membrane response as a function of the CS2-CS1 and CS1-US intervals. Animal Learning \& Behavior, 9, 304-315

KeHOE, E. J., \& Holt, P. E. (1984). Transfer across CS-US intervals and sensory modalities in classical conditioning of the rabbit. Animal Learning \& Behavior, 12, 122-128.

Kehoe, E. J., Morrow, L. D. \& Holt, P. E. (1984). General transfer across sensory modalities survives reductions in the original conditioned reflex in the rabbit. Animal Learning \& Behavior, 12, 129-136.

LEVINE, M. (1959). A model of hypothesis behavior in discrimination learning sets. Psychological Review, 66, 353-366.
Mackintosh, N. J. (1977). Stimulus control: Attentional factors. In W. K. Honig \& J. E. R. Staddon (Eds.), Handbook of operant behavior (pp. 481-513). Englewood Cliffs, NJ: Prentice-Hall.

Meck, W. H., \& CHURCH, R. M. (1982). Abstraction of temporal attributes. Journal of Experimental Psychology: Animal Behavior Processes, 8, 226-243.

Reinhold, D. B., \& Perkins, C. C. (1955). Stimulus generalization following different methods of training. Journal of Experimental Psychology, 49, 423-427.

Ricciardi, A. M., \& Treichler, F. R. (1970). Prior training influences on transfer to learning set by squirrel monkeys. Journal of Comparative and Physiological Psychology, 73, 314-319.

Riope Lle, A. J. (1953). Transfer suppression and learning sets. Journal of Comparative and Physiological Psychology, 46, 108-114.

RODGERS, J. P., THOMAS, D. R. (1982). Task specificity in nonspecific transfer and in extradimensional stimulus generalization in pigeons. Journal of Experimental Psychology: Animal Behavior Processes, 8 301-312.

SCANDrett, J., \& Gormezano, I. (1980). Microprocessor control and A-D data acquisition in classical conditioning. Behavior Research Methods \& Instrumentation, 12, 120-125.

Seraganian, P. (1979). Extradimensional transfer in the easy-to-hard effect. Learning and Motivation, 10, 39-57.

Seraganian, P., \& Popova, Y. I. (1976). Cross-modal transfer of a conditioned flexion response in dogs. Pavlovian Joumal of Biological Sciences, 11, 162-174

Tномаs, D. R. (1970). Stimulus selection, attention, and related matters. In J. H. Reynierse (Ed.), Current issues in animal learning (pp. 311-356). Lincoln: University of Nebraska Press.

Thomas, D. R., Freeman, F., SViniCKI, J. G., BURr, D. E., \& Lyons, J. (1970). Effects of extradimensional training on stimulus generalization. Joumal of Experimental Psychology Monographs, 83(1, Pt. 2).

Thomas, D. R., Miller, J. T., \& Svinicki, J. G. (1971). Nonspecific transfer effects of discrimination training in the rat. Journal of Comparative and Physiological Psychology, 74, 96-101.

WestbrooK, R. F., \& HoMEwood, J. (1982). The effects of a flavour toxicosis pairing upon long-delay, flavour aversion learning. Quarterly Journal of Experimental Psychology, 34B, 139-149.

YehLE, A. L., \& WARD, J. P. (1969). Cross-modal transfer of a specific discrimination in the rabbit. Psychonomic Science, 16, 269-270.

(Manuscript received June 12, 1984; revision accepted for publication October 29,1984 .) 